\title{
Chromogranin B Gene Ablation Reduces the Catecholamine Cargo and Decelerates Exocytosis in Chromaffin Secretory Vesicles
}

\author{
Jésica Díaz-Vera, ${ }^{1}$ Yézer G. Morales, ${ }^{1}$ Juan R. Hernández-Fernaud, ${ }^{2}$ Marcial Camacho, ${ }^{1}$ Mónica S. Montesinos, ${ }^{1}$ \\ Federico Calegari, ${ }^{3}$ Wieland B. Huttner, ${ }^{3}$ Ricardo Borges, ${ }^{1}$ and José D. Machado ${ }^{1}$ \\ ${ }^{1}$ Unit of Pharmacology, Medical School, and ${ }^{2}$ Proteomic Service, La Laguna University, 38071 La Laguna, Tenerife, Spain, and ${ }^{3}$ Max Planck Institute of \\ Molecular Biology and Genetics, 01307 Dresden, Germany
}

\begin{abstract}
Chromogranins/secretogranins (Cgs) are the major soluble proteins of large dense-core secretory vesicles (LDCVs). We have recently reported that the absence of chromogranin A $(\mathrm{CgA})$ caused important changes in the accumulation and in the exocytosis of catecholamines (CAs) using a CgA-knock-out ( $\mathrm{CgA}-\mathrm{KO})$ mouse. Here, we have analyzed a $\mathrm{CgB}$-KO mouse strain that can be maintained in homozygosis. These mice have $36 \%$ less adrenomedullary epinephrine when compared to $\mathrm{Chgb}^{+/+}$[wild type (WT)], whereas the norepinephrine content was similar. The total evoked release of CA was 33\% lower than WT mice. This decrease was not due to a lower frequency of exocytotic events but to less secretion per quantum $(\sim 30 \%)$ measured by amperometry; amperometric spikes exhibited a slower ascending but a normal decaying phase. Cell incubation with L-DOPA increased the vesicle CA content of WT but not of the CgB-KO cells. Intracellular electrochemistry, using patch amperometry, showed that L-DOPA overload produced a significantly larger increase in cytosolic CAs in cells from the $\mathrm{KO}$ animals than chromaffin cells from the WT. These data indicate that the mechanisms for vesicular accumulation of CAs in the $\mathrm{CgB}-\mathrm{KO}$ cells were saturated, while there was ample capacity for further accumulation in WT cells. Protein analysis of LDCVs showed the overexpression of $\mathrm{CgA}$ as well as other proteins apparently unrelated to the secretory process. We conclude that $\mathrm{CgB}$, like $\mathrm{CgA}$, is a highly efficient system directly involved in monoamine accumulation and in the kinetics of exocytosis from LDCVs.
\end{abstract}

\section{Introduction}

Chromogranins/secretogranins (Cgs) are acidic proteins consisting of single polypeptide chains that are mainly located within secretory vesicles such as chromaffin granules and large densecore vesicles (LDCVs) of monoaminergic neurons (Huttner et al., 1991; Taupenot et al., 2003). In these organelles, Cgs constitute the main protein component of the intravesicular matrix. However, most of the already described functions of $\mathrm{Cgs}$ are based on experiments studying chromogranin A ( CgA), while there is far less information available about the physiological roles of chromogranin B (CgB, previously called secretogranin I). Several functions have been proposed for $\mathrm{CgB}$, including the following: granule biogenesis and sorting (Natori and Huttner, 1996; Huh et al., 2003), $\mathrm{Ca}^{2+}$ sequestration and release (Yoo and Jeon, 2000), and a source of bioactive peptides (Strub

Received June 18, 2009; revised Nov. 10, 2009; accepted Nov. 16, 2009

J.D.-V. and Y.G.M. are recipients of fellowships from the Spanish Ministry of Science and Innovation (MICINN). J.D.M. has a CONSOLIDER contract (CSD2008-00005). This work was supported by MICINN Grant BFU2007-64963. We thank Agustin Castañeyra and Emilia Carmona for helping us with the immunocytochemistry images. We also thank the personnel of the animal house of the University of La Laguna for the maintenance of the mouse strains.

Correspondence should be addressed to Dr. Ricardo Borges, Unidad de Farmacología, Facultad de Medicina, Universidad de La Laguna, 38071 La Laguna, Tenerife, Spain. E-mail: rborges@ull.es.

F. Calegari's present address: Deutsche Forschungsgemeinschaft-Center for Regenerative Therapies, Dresden University of Technology, 01307 Dresden, Germany.

DOI:10.1523/JNEUROSCI.2894-09.2010

Copyright $\odot 2010$ the authors $\quad 0270-6474 / 10 / 300950-08 \$ 15.00 / 0$ et al., 1995; Winkler et al., 1998; Taupenot et al., 2003). Chromogranin B has recently grown in importance after the unexpected finding associating it with some classes of human diseases, such as schizophrenia (Landén et al., 1999; Marksteiner et al., 2000), Alzheimer's disease (Marksteiner et al., 2000), and hypertension (Zhang et al., 2009), as well as for its possible involvement in diabetes, which has been observed in mice (Obermüller et al., submitted).

An important property of Cgs is their ability to bind solutes that allow LDCVs to accumulate large amounts of catecholamines (CAs) while maintaining their isotonicity (Helle et al., 1985). This feature is essential for the maintenance of neurosecretory activity. Using a new mouse strain without CgA (Mahapatra et al., 2005), we have recently found important roles of CgA on CA exocytosis (Montesinos et al., 2008). However, there are no data currently available about the roles of the $\mathrm{CgB}$ on amine accumulation and exocytosis, the other main granin of LDCVs.

In the present study, we have analyzed mice with homozygous $(-/-)$ targeted ablation of the $\mathrm{CgB}$ locus (knock-out, $\mathrm{CgB}-\mathrm{KO}$ ). We have used proteomic studies to characterize the effects of the lack of $\mathrm{CgB}$ on the expression of LDCV proteins from adrenal chromaffin cells. Moreover, by combining single-cell amperometry and intracellular electrochemistry, we have directly studied the participation of $\mathrm{CgB}$ in the storage and in the release processes of CAs from adrenal chromaffin cells. 


\section{Materials and Methods}

Materials. Culture plates, sera, and culture media were from Nunc, Papain was purchased from Worthington. All other drugs were purchased from Sigma-Aldrich.

Chromogranin B KO mice. All animal procedures were performed in agreement with institutional and national guidelines and regulations. A detailed description of the generation of the $\mathrm{CgB}-\mathrm{KO}$ line is provided elsewhere (Obermüller et al., submitted). Briefly, a targeting construct was used to replace by homologous recombination 117 bases of the proximal promoter region and the first 29 bases of the coding sequence of CgB. Embryonic stem cells were subjected to double selection and clones screened by Southern blot analysis. Five clones positive for the recombination were injected into C57/Bl-6 blastocysts, and the offspring was inbred and outcrossed with $\mathrm{C} 57 \mathrm{BL} / 6 \mathrm{~J}$ mice to homogenize the genetic background. For genotyping, DNA isolation from mouse-tail biopsies was performed by proteinase $\mathrm{K}$ digestion followed by phenolchloroform purification as previously described (Sambrook et al., 1989). Genotyping was performed by PCR (Applied Biosystems 2720 Thermal Cycler). Primer sequences were as follows: F-chgb 5' -GAGCCGGACCCTTGTCCCTTCTTGCC-3'; R-chgb 5'-GCCTGACATCTCTGCAGAGAACACAG-3'. Primers F-chgb and R-chgb flank the region of the chgb gene disrupted by the insertion by homologous recombination that included herpes simplex virus thymidine kinase gene, $2.8 \mathrm{~kb}$ of $\mathrm{mCgB}$ proximal promoter region, the neomycin resistance gene, and the full genomic sequence, BglII-EcoRI excised, of intron 1 and exon 2 of the $\mathrm{mCgB}$ gene corresponding to $3.6 \mathrm{~kb}$. The expected amplification products were $574 \mathrm{bp}$ fragment from the wildtype (WT) allele and a $1.6 \mathrm{kbp}$ fragment from the KO allele.

Immunohistochemistry. Serial sections were prepared using a standard procedure and incubated overnight at room temperature in Trissaline, $\mathrm{pH} 7.6$, containing the following: anti-CgA 1:300 or anti-CgB 1:400. The procedure was followed by StreptABComplex Duet Reagent Set Mouse/Rabbit procedure (DAKO). The peroxidase reaction product was visualized through the standard diaminobenzidine reaction. Control experiments were performed without primary antibodies (supplemental Fig. 1, available at www.jneurosci.org as supplemental material).

HPLC analysis of CAs. Adrenal medullas were triturated on ice-cold lysis buffer containing perchloric acid $(0.05 \mathrm{~N})$, Triton X-100 (0.25\%), and dihydroxybenzylamine $(100 \mathrm{ng} / \mathrm{ml})$ as internal standard. The homogenates were centrifuged and cleared supernatants were analyzed by HPLC coupled with electrochemical detection (Borges et al., 1986).

Culture of mouse chromaffin cells. Cells were cultured from one-month old mice following the method of Sørensen (Sørensen et al., 2003; Machado et al., 2008). The cells were plated at an approximate density of $5 \times 10^{4}$ cells on 12 -mm-diameter poly-D-lysine-coated coverslips and used at room temperature between 0 and $2 \mathrm{~d}$ of culture.

Amperometry and data analysis. Carbon fiber microelectrodes of $5 \mu \mathrm{m}$ radius (Thornel P-55; Amoco) were prepared as described previously (Kawagoe et al., 1993). Electrodes were tested by flow injection analysis with norepinephrine. Amperometric measurements were performed with the carbon fiber microelectrode gently touching the cell membrane using an EPC-10 (HEKA Elektronik) (Machado et al., 2000). Cells were bathed in Krebs-HEPES solution (in mM): $\mathrm{NaCl}$ (140), $\mathrm{KCl}$ (5), $\mathrm{MgCl}_{2}$ (1.2), $\mathrm{CaCl}_{2}$ (2.5), glucose (11), and HEPES (10), pH $7.3(\mathrm{NaOH})$, and secretion was stimulated by $10 \mathrm{~s}$ pressure ejections of $5 \mathrm{~mm} \mathrm{Ba}^{2+}$ from a micropipette positioned $40 \mu \mathrm{m}$ from the cell.

Signals were low-pass filtered at $1 \mathrm{kHz}$ and collected at $4 \mathrm{kHz}$. Data analysis was performed using locally written macros for IGOR (Wavemetrics) (Segura et al., 2000) that extracted the following parameters from each spike (Table 1, inset): $I_{\max }$, maximum oxidation current, expressed in picoamperes; $t_{1 / 2}$, spike width at half-height, expressed in milliseconds; $Q$, spike net charge, expressed in picocoulombs; $m$, ascending slope of spike, expressed in picoamperes per millisecond. Two measurements were taken, $\mathrm{Ft}_{1}$ and $\mathrm{Ft}_{2}$ (falling times 1 and 2), to analyze the descending part of spikes as the time from the spike maximum point to reach the $I_{\max } /(e-1)$ and the $I_{\max } / e$ points of the spike, respectively (Machado et al., 2000; Segura et al., 2000). The recordings were alternated between
Table 1. Characteristics of secretory spikes obtained from chromaffin cells of $\mathrm{CgB}$ KO mice

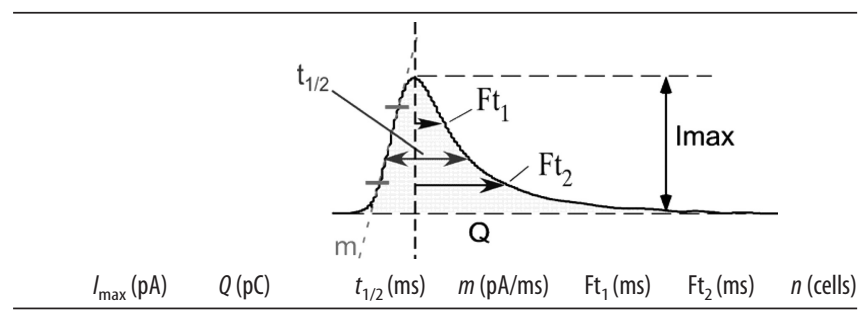

$\begin{array}{lllllllll}\text { WT } & 61.4 \pm 7.8 & 0.39 \pm 0.05 & 6.1 \pm 0.5 & 27.5 \pm 3.5 & 2.9 \pm 0.2 & 5.9 \pm 0.6 & 20\end{array}$

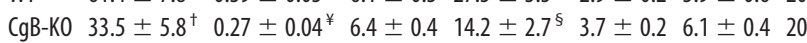

$\begin{array}{llllll}\text { Change }-45 \% & -31 \% & +5 \% & -48 \% & +28 \% & +22 \%\end{array}$

See Segura et al. (2000) for explanation. Data are expressed in the units in parentheses.

${ }^{\dagger} p=0.02 ;{ }^{*} p=0.054 ;{ }^{5} p=0.001$ (U Mann-Whitney).
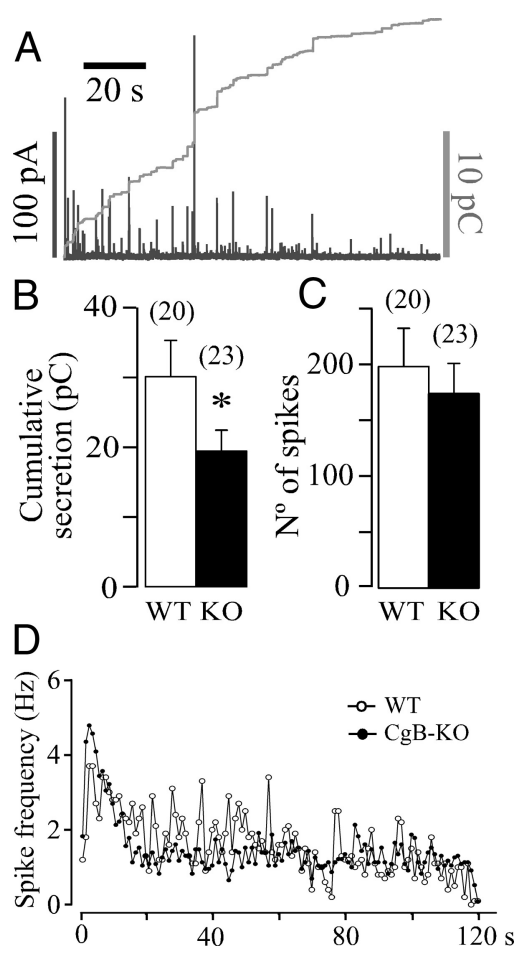

Figure 1. The secretory profile of chromaffin cells lacking $\mathrm{CgB} . A, A$ typical amperometric trace obtained from a $\mathrm{CgB}-\mathrm{KO}$ cell after a 10 s pressure application of $\mathrm{BaCl}_{2}(5 \mathrm{~mm})$; left black calibration bar is for the amperometry trace (in picoamperes) and the right gray bar for the integrated signal (in picocoulombs). $\boldsymbol{B}$, Quantification of the cumulated release after 2 min (means \pm SEM) expressed in picocoulombs. The number of cells used is in brackets. ${ }^{*} p=0.053$ (UMann-Whitney). Stimuli were applied at 0 s time. C, Total amount of spikes (means \pm SEM) counted for $2 \mathrm{~min}$ after stimulation. $\boldsymbol{D}$, Distribution of spikes expressed in hertz. Each point is the average of counting spikes at $1 \mathrm{~s}$ intervals.

CgB-KO and WT cells; no comparisons were made between experiments performed on different days. The kinetic parameters were calculated as mean values from at least 20 spikes/cell. The average values of spikes parameters recorded from each cell were considered as $n=1$ to avoid the deviations caused by the different number of spikes produced by each cell (Colliver et al., 2001).

Intracellular patch electrochemistry. Whole-cell patch amperometry was adapted from (Mosharov et al., 2003). The patch pipette solution contained the following (in mM): $\mathrm{CsOH}$ (140), $\mathrm{CsCl}$ (6), HEPES (6), $\mathrm{Na}-\mathrm{GTP}(0.3)$, and Mg-ATP (2) adjusted up to $\mathrm{pH} 7.2$ with gluconic acid; osmolarity, 300-315 mOsm. The procedure for electrode and pipette construction has been described previously (Dernick et al., 2005; Montesinos et al., 2008). Baseline was recorded under cell-attached con- 
figuration for at least $10 \mathrm{~s}$, and then the cell membrane was broken by suction to analyze the cytosolic amines.

Immunoblots. Adrenal medullas were removed and solubilized by homogenization as described previously (Montesinos et al., 2008). After determination of protein concentrations by bicinchoninic method, 20 $\mu \mathrm{g}$ of total protein/lane were separated on $10 \%$ SDS-polyacrylamide gels and blotted onto polyvinylidene difluoride membranes (Hybond-P, GE Healthcare) using a standard procedure. The following primary antibodies and dilutions were used: rabbit polyclonal raised against an epitope corresponding to amino acids 158-457 mapping at the $\mathrm{C}$ terminus of CgA of human origin (Santa Cruz Biotechnology catalog \#sc13090;) at 1:4000; polyclonal rabbit antiserum raised against bovine CgB (amino acids 55-68), a kind gift from Dr. M. H. MetzBoutigue (INSERM Unite 575, Strasbourg, France), 1:4000; anti-secretogranin II (SgII) polyclonal antibody (against mouse secretoneurin fragment), a kind gift from Dr. R. Fischer-Colbrie (Innsbruck University, Innsbruck, Austria), at 1:3000 dilution; and a monoclonal mouse anti-tyrosine hydroxylase (Sigma, catalog \#T2928) (1:8000). Anticytochrome $\mathrm{C}$ oxidase (COX1) is a polyclonal antibody against a peptide mapping near the C terminus of COX1 of human origin (Santa Cruz Biotechnology, catalog \#sc23982), and anti-tubulin antibody against $\beta \mathrm{III}$ isoform monoclonal antibody was used (Millipore Bioscience Research Reagents). After incubation with secondary antibodies (antirabbit/anti-mouse/anti-goat horseradish peroxidase-conjugated IgG, 1:5000), the signal was developed with the ECL + system (GE Healthcare). Chemiluminescence signals were detected by an imaging system (Gel Logic 440, Kodak) and analyzed using the software provided by the manufacturer.

Chromaffin granule isolation. Adrenal medullas were triturated using a glass homogenizer in an ice-cold buffer containing the following (in $\mathrm{mm}$ ): sucrose (300), EDTA (1), $\mathrm{MgSO}_{4}$ (1), and HEPES (10), pH 7.0, and centrifuged for $10 \mathrm{~min}$ at $1000 \times \mathrm{g}$ at $4^{\circ} \mathrm{C}$. The supernatant was collected and centrifuged at $10,000 \times g$ for $20 \mathrm{~min}$ at $4^{\circ} \mathrm{C}$. The resultant pellet was resuspended in an Optiprep (Nycomed Pharma) dilution medium (in mM): sucrose (300), EDTA (6), $\mathrm{MgSO}_{4}$ (6), and HEPES (60), pH 7, and overlaid on a discontinuous gradient $8 / 18 \%$ OptiPrep. The gradient was made in LoBind tubes (Eppendorf) to prevent protein loss and centrifuged at $10,000 \times g$ for $10 \mathrm{~h}$ at $4^{\circ} \mathrm{C}$. Standard sucrose discontinuous gradient (Smith and Winkler, 1967) was also used for comparison purposes. The pellet was collected and directly resuspended in $20 \mu \mathrm{l}$ of denaturing buffer composed of $8 \mathrm{~m}$ urea, $4 \%$ CHAPS, $40 \mathrm{~mm}$ Tris base, 65 mM dithioerythritol, $0.05 \%$ SDS, and a trace of bromophenol blue for $2 \mathrm{D}$ analysis. Succinate dehydrogenase was analyzed as described previously (Munujos et al., 1993).

Two-dimensional electrophoresis and MALDI-TOF-MS. A minimum of 40 medullas was required for each $2 \mathrm{D}$ electrophoresis. Vesicle samples containing $\sim 100 \mu \mathrm{g}$ of total protein were applied to the basic end of a glass capillary tube gel to perform the isoelectric focus. Capillary tubes were filled, for separation in the $4-8 \mathrm{pH}$ range, with solution containing $3 \%$ acrylamide, $7 \mathrm{M}$ urea, $0.6 \%$ Triton X-100, 0.75\% ampholytes $\mathrm{pH} 5-8$, $0.22 \%$ ampholytes $\mathrm{pH} 3-10,0.22 \%$ ampholytes $\mathrm{pH}$ 7-9, 0.045\% TEMED, and $0.08 \%$ APS. Isoelectric focus steps consisted of $1 \mathrm{~h}$ at 100 and $300 \mathrm{~V}$, respectively, followed by $17.5 \mathrm{~h}$ at $1 \mathrm{kV}$ and $30 \mathrm{~min}$ at $2 \mathrm{kV}$. Then, the capillaries were equilibrated for $15 \mathrm{~min}$ in reducing buffer containing 50 $\mathrm{mm}$ TrisHCl, $\mathrm{pH} 8.8,30 \%$ glycerol, $6 \mathrm{~m}$ urea, 2\% SDS, and 1\% DTT, followed by a blocking step in a similar buffer containing $2.5 \%$ iodoacetamide instead of DTT, for another $15 \mathrm{~min}$. The capillary gels were then transferred to the top of $18 \times 18 \mathrm{~cm}, 1.5$-mm-thick, $10 \%$ polyacrylamide gels (SDS-PAGE) and embedded in $0.5 \%$ low-melting agarose containing a trace of bromophenol blue. SDS-PAGE was run at $15^{\circ} \mathrm{C}$, initially at
Table 2. LDCV from CgB-KO chromaffin cells cannot uptake more catecholamines

\begin{tabular}{lllll}
\hline & $I_{\max }(\mathrm{pA})$ & $Q(\mathrm{pC})$ & $t_{1 / 2}(\mathrm{~ms})$ & $n$ \\
\hline WT & $20.7 \pm 4.4$ & $0.31 \pm 0.1$ & $11.1 \pm 0.9$ & 10 \\
WT, L-DOPA & $51.7 \pm 7.6^{\dagger}$ & $0.95 \pm 0.2^{¥}$ & $16.1 \pm 1.7^{\S}$ & 10 \\
CgB-KO & $35.3 \pm 3.2$ & $0.43 \pm 0.03$ & $7.9 \pm 0.6$ & 11 \\
CgB-KO, L-DOPA & $36.2 \pm 2.3$ & $0.33 \pm 0.04$ & $6.8 \pm 0.9$ & 10 \\
\hline
\end{tabular}

Cells from WT or CgB-KO mice were incubated with culture media or $100 \mu \mathrm{M} \mathrm{L-DOPA}$ for 90 min. Exocytosis was monitored by single cell amperometry. $I_{\max }$, Spike maximal height; $Q$, net CA content; and $t_{1 / 2}$, the spike duration at half-height. ${ }^{\dagger} p=0.007 ;{ }^{*} p=0.011 ;{ }^{8} p=0.035$. Values of $p$ were obtained with the Mann-Whitney test. Note that the experiments done with WT and CgB-KO cells were conducted in different days using different electrodes; for this reason quantitative analysis between these two groups cannot be performed. 
$1.30(\mathrm{CgB}-\mathrm{KO})$. There was a $36 \%$ reduction in epinephrine, but norepinephrine and dopamine content were not affected.

Carbon fiber electrodes were used to quantify the secretory responses and the single-event exocytotic characteristics. Figure $1 A$ shows a typical secretory profile from a $\mathrm{KO}$ cell obtained after a $10 \mathrm{~s} \mathrm{BaCl}_{2}$ stimulus. The cumulative secretion detected at the electrode surface was assessed by integrating the amperometric trace for 2 min after stimuli. A program (written in IGOR Pro) was designed to prevent the addition of nonamperometrical signal caused by the asymmetrical distribution of noise; this program is freely available upon request. The average secretion data are summarized in Figure $1 B$, chromaffin cells from $\mathrm{CgB}-\mathrm{KO}$ mice released $\sim 33 \%$ less than WT. To know whether this decrease was caused by a reduction in the number of exocytotic events, secretory spikes were counted and plotted as displayed in Figure $1 C$. The temporal distribution of spikes for 2 min shows that the secretory profiles of both groups were similar and that the number of exocytotic events detected was also similar (Fig. $1 D)$. As a conclusion, the absence of $\mathrm{CgB}$ does not seem to affect the secretory machinery.

\section{Characterization of single-event exocytosis}

Because a reduction in the number of spikes was not the cause of the reduced secretion of $\mathrm{CgB}-\mathrm{KO}$ cells a detailed study of single exocytotic events was performed using amperometry. The analysis of the quantal size of exocytosis indicates a clear reduction in the amount of CAs secreted per quantum. This effect was accompanied by a deceleration of the initial part of the exocytotic process as observed in the ascending part of the spike (Table 1; see Fig. $5 A$ ). The number of measurable prespike features "feet" was lower in the KO cells mainly due to the smaller sizes of the spikes. However, no significant differences in the duration, $I_{\max }$, and net charge of the foot were found when compared to WT cells.

Data from Table 1 indicate that the reduction in the granule content of amines $(Q)$ mainly affects the parameters that measure the initial exit of CAs $\left(I_{\max }\right.$ and $m$ ) rather than those that quantify the latter part of the release $\left(t_{1 / 2}, \mathrm{Ft}_{1}\right.$, and $\left.\mathrm{Ft}_{2}\right)$. The lack of $\mathrm{CgB}$ and/or the subsequent overexpression of other vesicular proteins, see below, seem to modify the mechanisms that retain the solutes inside LDCVs.

To analyze the relationship between amine concentration reaching the electrode and the amine content in LDCVs in more detail, we plotted $I_{\max }$ versus $Q$ (see Fig. $5 B$ ). Spikes from both groups exhibited a clear linear relationship; however, the slopes differed markedly. These data indicate that spikes with similar quantal sizes $(Q)$ had lower spike peaks $\left(I_{\max }\right)$ and that, in the absence of $\mathrm{CgB}$ and overexpression of $\mathrm{CgA}$ regardless of the size of the vesicles, the concentration of amines reaching the electrode surface turned out to be lower.

In a recent paper, we described that the uptake of newly synthesized CAs was impaired in chromaffin cells from $\mathrm{CgA}-\mathrm{KO}$ (Montesinos et al., 2008). For a comparison of the effects of a lack of either of the Cgs, we studied the effects of CA overload in the exocytotic characteristics in LDCVs lacking CgB. The CA natural precursor-L-DOPA- has the advantage that it is highly permeable through the cell membrane, bypassing tyrosine hydroxylase, the limiting step in the synthetic chain. Previous experiments were performed to determine the best conditions for L-DOPA incubation $\left(100 \mu \mathrm{M}\right.$ for $90 \mathrm{~min}$ at $\left.37^{\circ} \mathrm{C}\right)$. Results are summarized in Table 2. Acute CA overload resulted in an approximately threefold increase in the quantum size $(Q)$ of individual exocytotic events in chromaffin cells from WT mice. This increase in the vesicular content of amines was also evident in both the spike

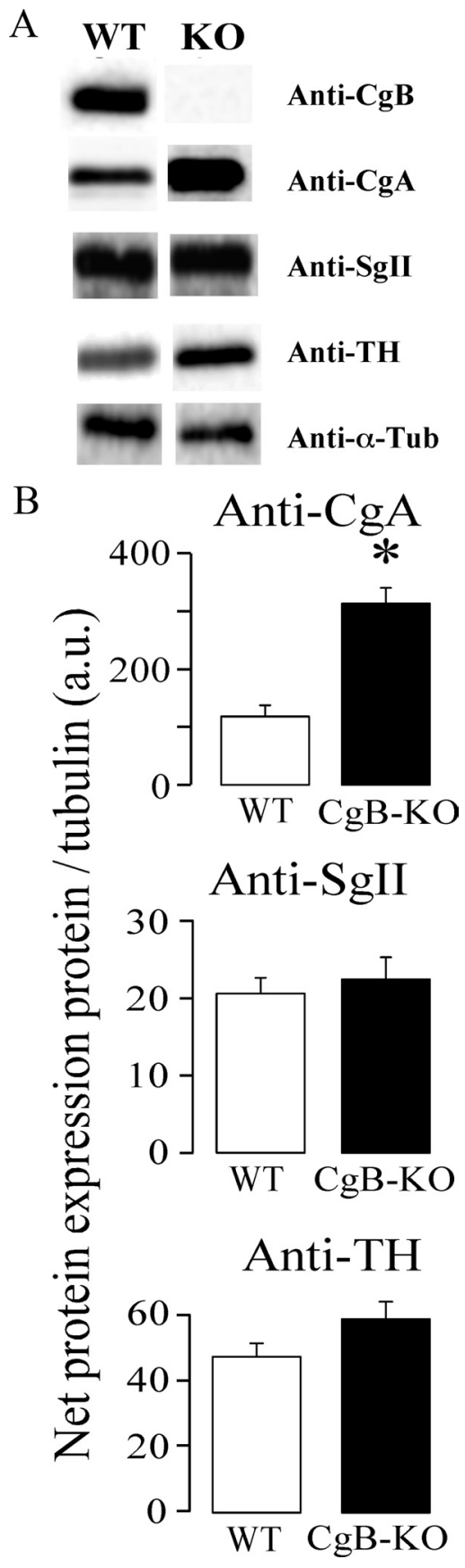

Figure 3. Adrenal $\mathrm{CgA}$ is overexpressed in $\mathrm{CgB}-\mathrm{KO}$ mice. A, Typical Western blots from adrenal medullary tissues confirming the lack of $\mathrm{CgB}$ and the overexpression of $\mathrm{CgA} . \alpha$-Tubulin was used as internal loading control. $\boldsymbol{B}$, Pooled data from three different experiments. Neither Sgll nor tyrosine hydroxylase (TH) levels were affected. ${ }^{*} p=0.03$, Mann-Whitney test.

height $\left(I_{\max }, 2.5\right.$ times $)$ and the overall spike duration $\left(t_{1 / 2}, 1.5\right.$ times). However, LDCVs from KO mice could not uptake more CAs, and no change was observed in the kinetics of exocytosis. The lack of $\mathrm{CgB}$ did not affect the falling part of spikes, as $\mathrm{Ft}_{1}$ and $\mathrm{Ft}_{2}$ were not modified by L-DOPA treatment (data not shown).

\section{Effects on free cytosolic amines}

We conducted experiments using intracellular electrochemistry (Fig. 2A) to study the basal free cytosolic CA and its overload with L-DOPA. Figure $2 B$ shows a typical recording of amine oxidation after the whole-cell configuration is assessed. Pargyline $(10 \mu \mathrm{M})$ 
was always present to prevent CA catabolism by monoaminooxidase. As occurred with the CgA-KO chromaffin cells, basal CAs of CgB-KO cells were consistently lower than WT cells (Fig. 2C). However, incubation with L-DOPA resulted in a larger increase in the free cytosolic catechols detected by the carbon fiber electrode, probably because $\mathrm{CgB}-\mathrm{KO}$ secretory vesicles cannot take more CAs. A large number of secretory spikes are frequently observed upon cell membrane disruption and the net charge from these spikes was subtracted from the trace (Fig. $2 B$, inset).

\section{Protein characterization}

Western blots confirmed the absence of $\mathrm{CgB}$ and the overexpression of CgA (2.6 times); however, no statistical changes occurred in the third chromogranin SgII (Fig. 3). In an effort to find out whether other vesicular proteins could be upregulated when $\mathrm{CgB}$ was absent, a careful analysis of the proteins present in chromaffin vesicles was performed. We compared the separation properties of sucrose and Optiprep (supplemental Fig. 2, available at www.jneurosci.org as supplemental material) to improve the purification method of LDCVs. Fraction 7 from ultracentrifugation Optiprep gradients was chosen because it contained CgA but not appreciable amounts of the mitochondrial marker COX1, which also coincides with the distribution of succinate dehydrogenase (data not shown).

The 2D typical gels from the enriched LDCV fractions corresponding to the WT are shown in Figure 4. However, despite the purification performed, some contamination from other cellular sources was seen in the MALDI-TOF analysis. The proteomic study confirmed the absence of $\mathrm{CgB}$ and the overexpression of CgA. Other vesicular proteins also seem to be affected (Table 3 ). We could not identify 5 out of 22 spots detected as up- or downexpressed proteins. Other proteins described as being present in LDCVs (Wegrzyn et al., 2007): ubiquinol-cytochrome C reductase core protein 1 and ATP synthase, $\mathrm{H}^{+}$transporting mitochondrial F1 complex, $\beta$ subunit were also detected.

\section{Discussion}

We recently described the importance of $\mathrm{CgA}$ in the storage and exocytosis of CAs (Montesinos et al., 2008), using a mouse line lacking CgA (Mahapatra et al., 2005). The main finding came from the analysis of single exocytotic events, which showed the impairment in the cargo capacity of LDCVs together with the acceleration of their emptying. LDCVs from CgA-KO cells overexpressed CgB by $\sim 2.2$ times, probably as a result of compensatory mechanisms. $\mathrm{CgA}$ and $\mathrm{CgB}$ share many features (Huttner et al., 1991), such as having an acidic nature (Helle et al., 1985), being a source of biologically active peptides (Taupenot et al., 2003), and binding amines and $\mathrm{Ca}^{2+}$ (Winkler and Fischer-Colbrie, 1992). The generation of a new mouse line lacking CgB (Obermüller et al., submitted), the other quantitatively major intravesicular protein, opens up the possibility of exploring its functional role in the accumulation and exocytosis of CAs. The CgB-KO animals are viable and fertile, although they display glucose intolerance reminiscent of type-2 diabetes despite nor-
A

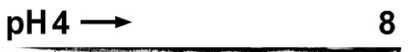

$\mathrm{B}$ $8 \mathrm{pH} 4 \longrightarrow \quad 8$

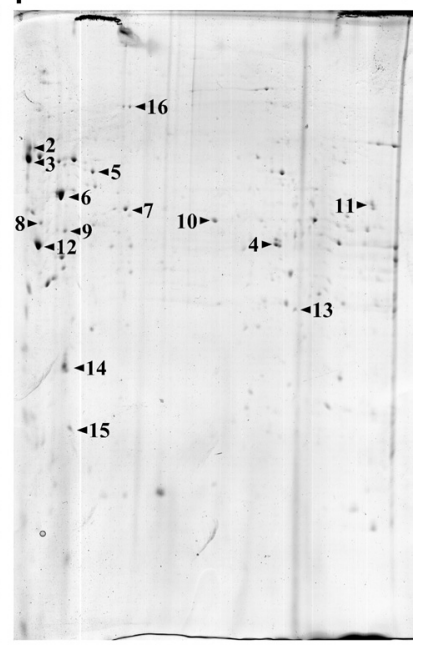

WT

\section{$\mathrm{CgB}-\mathrm{KO}$}

Figure 4. Two-dimensional gel electrophoresis of chromaffin secretory vesicles from WT and CgB-K0 mice. Fractions 3 to 5 from optiprep gradients were used to perform the 2D SDS-PAGE. Panels show original gels stained with colloidal Coomassie blue. Proteins were identified by MALDI-TOF (see Table 3).

mal synthesis and regulated exocytosis of insulin LDCVs (Obermüller et al. submitted).

Chromogranin B has been associated with the genesis of LDCVs (Natori and Huttner, 1996; Huh et al., 2003). However, chromaffin cells from $\mathrm{CgB}-\mathrm{KO}$ mice apparently keep their stimulus-secretion coupling intact (Fig. 1C,D); it therefore becomes clear that $\mathrm{CgB}$ is not essential for maintaining LDCV genesis. It is plausible that overexpression of other proteins, activated by the lack of $\mathrm{CgB}$, can assume these roles. One possible candidate is CgA (Kim et al., 2005), which also possesses a terminal loop in the same position as $\mathrm{CgB}$ and that has been involved in the recognition and initiation of the budding process in the trans-Golgi (Glombik et al., 1999).

To quantify the functional effects of the lack of $\mathrm{CgB}$ on the secretory responses, and to compare these with what we observed with $\mathrm{CgA}-\mathrm{KO}$, we conducted experiments using single-cell amperometry. This technique allows the following: (1) the analysis of individual exocytotic events, (2) the temporal distribution of fusion events, and (3) the quantification of total secretion occurring at the surface covered by the electrode. The 33\% reduction in the total CA release was not caused by a decrease in the number of exocytotic events (Fig. 1C) but by a decrease (31\%) in the amount of catecholamines per vesicle $(Q)$ (Table 1$)$. This was similar to that found in CgA-KO chromaffin cells (34\%) (Montesinos et al., 2008). However, the detailed analysis revealed important differences in the kinetics of exocytosis (Fig. $5 A$ ). In crude terms, quantal release from single vesicle was accelerated in $\mathrm{CgA}-\mathrm{KO}$ cells but decelerated in the CgB-KO (Table 1). The lack of $\mathrm{CgB}$ and/or overexpression of CgA made the rising part of amperometrical spikes slower. In addition, Figure $5 B$ shows that LDCVs with similar amine content, contrary to that observed in CgA-KO, had smaller $I_{\max }$ in the $\mathrm{CgB}-\mathrm{KO}$ cells. Our results indicate that the apparent affinity of CAs for the LDCV matrix was bigger or the swelling process of the vesicle after fusion was reduced.

It is not easy to associate the changes in Cg composition to the alterations in the kinetics of exocytosis provided that, to the best 
Table 3. Proteins present in LDCV of chromaffin cells identified by MALDI-TOF MS

\begin{tabular}{|c|c|c|c|c|c|c|c|c|c|}
\hline ID-Spot & Protein identity & NCBI No (gi) & $\mathrm{MW}(\mathrm{Da})$ & $\mathrm{pl}$ & $\begin{array}{l}\text { Matched } \\
\text { peptide }\end{array}$ & $\begin{array}{l}\text { Sequence } \\
\text { coverage (\%) }\end{array}$ & $\begin{array}{l}\text { Mascot } \\
\text { score }\end{array}$ & $\begin{array}{l}\text { Missed } \\
\text { cleavage }\end{array}$ & Fold change \\
\hline 1 & Chromogranin-B & 50409 & 77,895 & 5.01 & 14 & 22 & 122 & 3 & Only WT \\
\hline 2 & Secretogranin II, precursor & 417771 & 70,600 & 4.69 & 18 & 31 & 194 & 2 & * \\
\hline 3 & Chromogranin-A & 20071660 & 51,929 & 4.65 & 15 & 27 & 114 & 4 & * \\
\hline 4 & Aldehyde dehydrogenase 2, mitochondrial & 26330458 & 57,015 & 7.53 & 11 & 25 & 146 & 1 & +2.4 \\
\hline 5 & Albumin & 26341396 & 67,013 & 5.49 & 11 & 21 & 94 & 1 & -2.3 \\
\hline 6 & Heat shock protein 1 (Chaperonin) & 26353954 & 61,089 & 5.67 & 9 & 20 & 87 & 1 & +1.8 \\
\hline 7 & Protein disulfide isomerase-associated 3 & 26353794 & 57,103 & 5.78 & 9 & 23 & 106 & 2 & +1.5 \\
\hline 8 & Vimentin & 2078001 & 51,590 & 4.96 & 8 & 31 & 79 & 1 & Only KO \\
\hline 9 & Fibrinogen, $\gamma$ polypeptide & 18043449 & 50,044 & 5.54 & 18 & 37 & 137 & 2 & Only KO \\
\hline 10 & Fibrinogen, $\beta$ polypeptide & 21619364 & 55,402 & 6.68 & 10 & 23 & 100 & 1 & Only KO \\
\hline 11 & Fibrinogen, $\alpha$ polypeptide & 13529485 & 61,801 & 7.16 & 23 & 33 & 175 & 2 & Only KO \\
\hline 12 & ATP synthase, $\mathrm{H}^{+}$transporting mitochondrial F1 complex, $\beta$ subunit & 28302366 & 56,265 & 5.19 & 19 & 55 & 230 & 1 & +1.3 \\
\hline 13 & Acyl-coenzyme A dehydrogenase, short chain & 192659 & 45,203 & 8.96 & 9 & 28 & 74 & 2 & Only KO \\
\hline 14 & Apolipoprotein E & 54035417 & 35,901 & 5.56 & 12 & 28 & 91 & 2 & +2.6 \\
\hline 15 & Prohibitin & 12832901 & 29,859 & 5.57 & 9 & 55 & 132 & 1 & +1.5 \\
\hline 16 & Chapsin 110/ Discs large homolog 2 (Drosophila) & 26338173 & 54,421 & 6.93 & 6 & 18 & 68 & 1 & -2.1 \\
\hline
\end{tabular}

*Not quantified, multiple postprocessing proteins.

of our knowledge, there are no data available concerning the binding properties of $\mathrm{CgB}$ to CAs. Studies using bovine $\mathrm{CgA}$ "in vitro" confirm the $\mathrm{Ca}^{2+}$-dependent binding of CAs to CgA (Westermann et al., 1988). Chromogranin A has been described as a low-affinity ( $K_{\mathrm{d}}=2.1 \mathrm{~mm}$ for norepinephrine) and highcapacity (32 mol of norepinephrine/mol of CgA) buffer (Videen et al., 1992). It is difficult to transfer cow data to mice because bovine LDCV contains 10 times more CgA than CgB (Winkler and Fischer-Colbrie, 1992); although the quantitative distribution $\mathrm{CgA} / \mathrm{CgB}$ in mice has not been published, our data indicate a much larger proportion of $\mathrm{CgB}$ (Fig. 2). The binding ability of Cgs might be affected by their quaternary structure, Cgs form homotetramers and heterotetramers under the physiological conditions of LDCV media (high $\mathrm{Ca}^{2+}$ and ATP together with low $\mathrm{pH}$ ) (Yoo and Lewis, 1996). However, CgB-KO cells cannot generate heterotetramers, and the affinity of the vesicular matrix for CAs would change despite the fact that CgA is overexpressed $\sim 2.6$ times. The main consequence is the different release profile observed in the amperometric spikes from $\mathrm{CgA}-\mathrm{KO}$ and $\mathrm{CgB}-\mathrm{KO}$ chromaffin cells.

Secretory vesicles from CgB-KO cells were unable to uptake more CAs, as they did not increase their content when cells were overloaded with the CA precursor L-DOPA (Table 2). This suggests that secretory vesicles from $\mathrm{CgB}-\mathrm{KO}$ cells were saturated, leaving no room for newly synthesized species. Data from intracellular electrochemistry (Fig. 2) gave additional support to this hypothesis, as L-DOPA greatly increased the free cytosolic levels of catechols as compared to WT. We could not quantify the amount of vesicular amines that remained free in the so-called "halo." However, this should constitute a small amount, as no changes were observed after L-DOPA treatment.

The qualitative HPLC analysis of adrenal CAs also supports this view. Epinephrine content was largely reduced in $\mathrm{CgB}-\mathrm{KO}$ cells but dopamine or norepinephrine remained unaffected. This can be explained because epinephrine synthesis step occurs in the cytosol and the amine uptake to LDCVs is impaired, and epinephrine has to spend more time in the cytosol being degraded by monoaminooxidase.

To address the notion that the differences observed in the storage and exocytosis are related to the intravesicular protein composition, we performed a proteomic study. Although a report on whole rat adrenal glands has recently been published
(Pascual et al., 2009), this is to our knowledge the first study performed on the LDCVs from mice. The very low amounts of purified vesicles forced us to use a large number of animals. Special care was taken to obtain a large as possible amount of highly purified vesicles to conduct $2 \mathrm{D}$ electrophoretic analysis. The process did not simply consist of miniaturizing the procedure for bovine LDCVs as mouse vesicles are smaller and because the lack of $\mathrm{CgB}$ might change the centrifugation density. The immunoreactivity of CgA as LDCV marker was present in all the fractions from both the sucrose and Optiprep gradient suggesting its release from broken vesicles. However, the mitochondrial marker COX1 and succinate dehydrogenase activity was absent in fractions 3-7 in the Optiprep gradient (supplemental Fig. 2, available at www.jneurosci.org as supplemental material). We used fraction 7 to perform the protein characterization.

Chromogranin A was overexpressed in CgB-lacking animals (Fig. 3). However, the exact quantification of Cgs was difficult because they were usually accompanied by fragments resulting from intravesicular proteolysis (Lee and Hook, 2009). The lack of $\mathrm{CgB}$ revealed the expression of other proteins whose expression could compensate the lack of $\mathrm{CgB}$. We combed the areas of the $2 \mathrm{D}$ gels where other granins should be present but none of them were overexpressed. The proteins whose changes in expression were detected are depicted in Table 3. These proteins can be roughly grouped into the following: typical LDCVs (ID spots $1-3)$, classically associated to mitochondria $(4,12,13$, and 15), involved in protein folding (6 and 7), cytoskeletal (8), and "unexpected proteins" (5-11, 14, and 16). Predictably, CgB was not present in the KO material, but SgII did not seem to be affected, although its precise quantification was complex as explained above. Despite the fact that COX1 was not detected by Western blotting (supplemental Fig. 2, available at www.jneurosci.org as supplemental material), a number of mitochondrial-related proteins were overexpressed in the LDCV-enriched fraction of $\mathrm{CgB}-\mathrm{KO}$; it is possible that they come from mitochondrial contamination. The $\mathrm{CgB}-\mathrm{KO}$ mouse lacks several $\mathrm{CgB}$-derived peptides, and it is expected that these animals have more CgA-derived ones. It is likely that some of the changes observed in the granule protein profile could be originated by an altered metabolic glucidic or lipidic profile (Obermüller et al., submitted).

The fact that the marked reduction of $\mathrm{CgB}$ in brain neuron terminals (Marksteiner et al., 2000) and a polymorphism in apo- 

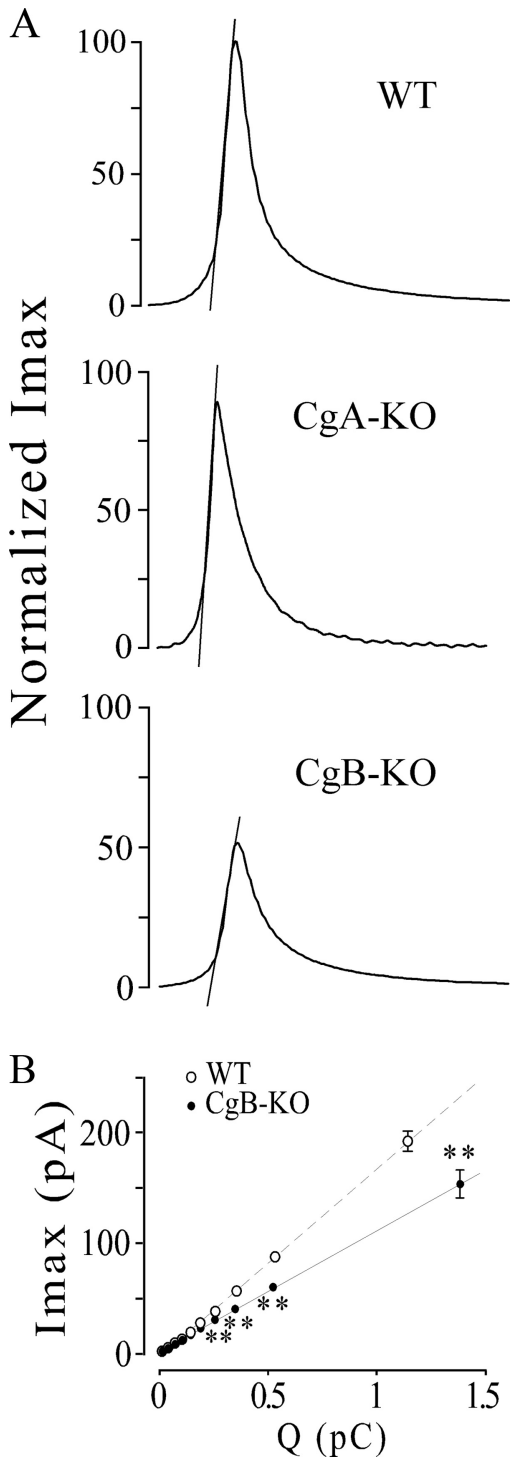

Figure 5. Kinetics profiles of amperometric spikes from $\mathrm{CgA}$ - or $\mathrm{CgB}-\mathrm{KO}$ chromaffin cells. $A$, Traces illustrate the kinetics changes observed in the exocytosis from cells lacking in $\mathrm{CgA}$ or $\mathrm{CgB}$. Spikes were constructed by averaging spikes; their corresponding values of $I_{\text {max }} t_{1 / 2}, m$, $\mathrm{Ft}_{1}$, and $\mathrm{Ft}_{2}$ coincide with the values given in Table 1 of a previous paper (Montesinos et al., 2008) and from Table 1 of this paper. Discontinuous lines show the ascending slopes $(m)$ obtained by linear fit of $25-75 \%$ segment of the ascending portion of spikes. $B$, Spike amplitude versus quantal size of secretory spikes from $\mathrm{CgB}-\mathrm{KO}\left(\mathrm{CgB}^{-1-}\right)$ and WT mice. All spikes (from WT and $(\mathrm{gB}-\mathrm{KO})$ were pooled regardless of whether they were from WT or KO cells and then distributed into 10 intervals of increasing charge containing the same number of spikes. The spikes were then split into WT and $\mathrm{K} 0$, and their $I_{\text {max }}$ (mean $\pm \mathrm{SEM}$ ) was analyzed. Note that, at similar quantal size, the spikes from CgB-KO have a smaller $I_{\text {max }}$ than WT. U Mann-Whitney with the correction of Bonferroni, ${ }^{* *} p<0.001$. Data are averaged from the spikes of Table 1.

lipoprotein E have been associated with Alzheimer's disease, together with the reduction observed in the expression of chapsin 110 , makes these animals potentially interesting as a model of neurodegenerative diseases. Chaperonin and disulfide isomerase 3 -associated protein are involved in the folding processes that occur in the endoplasmic reticulum and could be packaged into LDCVs. Special mention should be made regarding fibrinogen; the three chains $(\alpha, \beta$, and $\gamma$ ) were only present in the LDCVs of the $\mathrm{CgB}-\mathrm{KO}$. In addition to its crucial role in the clot formation, fibrinogen has recently been associated with the sorting of constitutive vesicles that use $\alpha_{1}$-anti-trypsin as a recognizing recep- tor (Gerdes and Glombik, 1999). A number of well established vesicular proteins, for instance dopamine- $\beta$-hydroxylase, were not quantified because they did not change their expression when $\mathrm{CgB}$ was absent. As the amount of starting material was so small, it is likely that some proteins were undetectable (Apps, 1997).

Our data provide the first direct evidence implicating $\mathrm{CgB}$ in vesicular storage and in the exocytotic release of CAs. In addition, we demonstrate that genesis of LDCVs is maintained in the absence of $\mathrm{CgB}$. These data indicate that the mechanisms for vesicular accumulation of CAs in CgB-KO cells were saturated, while there was ample capacity for further accumulation in WT cells. Protein analysis of LDCVs showed the overexpression of CgA as well as other proteins apparently unrelated to the secretory process. We conclude that $\mathrm{CgB}$, like $\mathrm{CgA}$, is a highly efficient system directly involved in monoamine accumulation and in the kinetics of exocytosis from LDCVs.

\section{References}

Apps DK (1997) Membrane and soluble proteins of adrenal chromaffin granules. Semin Cell Dev Biol 8:121-131.

Borges R, Sala F, Garcia AG (1986) Continuous monitoring of catecholamine release from perfused cat adrenals. J Neurosci Methods 16:289-300.

Colliver TL, Hess EJ, Ewing AG (2001) Amperometric analysis of exocytosis at chromaffin cells from genetically distinct mice. J Neurosci Methods 105:95-103.

Dernick G, Gong LW, Tabares L, Alvarez de Toledo G, Lindau M (2005) Patch amperometry: high-resolution measurements of single-vesicle fusion and release. Nat Methods 2:699-708.

Gerdes HH, Glombik MM (1999) Signal-mediated sorting to the regulated pathway of protein secretion. Ann Anat 181:447-453.

Glombik MM, Kromer A, Salm T, Huttner WB, Gerdes HH (1999) The disulfide-bonded loop of chromogranin B mediates membrane binding and directs sorting from the trans-Golgi network to secretory granules. EMBO J 18:1059-1070.

Helle KB, Reed RK, Pihl KE, Serck-Hanssen G (1985) Osmotic properties of the chromogranins and relation to osmotic pressure in catecholamine storage granules. Acta Physiol Scand 123:21-33.

Huh YH, Jeon SH, Yoo SH (2003) Chromogranin B-induced secretory granule biogenesis: comparison with the similar role of chromogranin $\mathrm{A}$. J Biol Chem 278:40581-40589.

Huttner WB, Gerdes HH, Rosa P (1991) The granin (chromogranin/secretogranin) family. Trends Biochem Sci 16:27-30.

Kawagoe KT, Zimmerman JB, Wightman RM (1993) Principles of voltammetry and microelectrode surface states. J Neurosci Methods 48:225-240.

Kim T, Zhang CF, Sun Z, Wu H, Loh YP (2005) Chromogranin A deficiency in transgenic mice leads to aberrant chromaffin granule biogenesis. J Neurosci 25:6958-6961.

Landén M, Grenfeldt B, Davidsson P, Stridsberg M, Regland B, Gottfries CG, Blennow K (1999) Reduction of chromogranin A and B but not $C$ in the cerebrospinal fluid in subjects with schizophrenia. Eur Neuropsychopharmacol 9:311-315.

Lee JC, Hook V (2009) Proteolytic fragments of chromogranins A and B represent major components of chromaffin granules, illustrated by 2-D proteomics with NH2-terminal Edman peptide sequencing and MALDITOF MS. Biochemistry 48:5254-5262.

Machado DJ, Montesinos MS, Borges R (2008) Good practices in single-cell amperometry. Methods Mol Biol 440:297-313.

Machado JD, Segura F, Brioso MA, Borges R (2000) Nitric oxide modulates a late step of exocytosis. J Biol Chem 275:20274-20279.

Mahapatra NR, O'Connor DT, Vaingankar SM, Hikim AP, Mahata M, Ray S, Staite E, Wu H, Gu Y, Dalton N, Kennedy BP, Ziegler MG, Ross J, Mahata SK (2005) Hypertension from targeted ablation of chromogranin A can be rescued by the human ortholog. J Clin Invest 115:1942-1952.

Marksteiner J, Lechner T, Kaufmann WA, Gurka P, Humpel C, Nowakowski C, Maier H, Jellinger KA (2000) Distribution of chromogranin B-like immunoreactivity in the human hippocampus and its changes in Alzheimer's disease. Acta Neuropathol 100:205-212.

Montesinos MS, Machado JD, Camacho M, Diaz J, Morales YG, Alvarez de la Rosa D, Carmona E, Castañeyra A, Viveros OH, O'Connor DT, Mahata SK, Borges R (2008) The crucial role of chromogranins in storage and 
exocytosis revealed using chromaffin cells from chromogranin A null mouse. J Neurosci 28:3350-3358.

Mosharov EV, Gong LW, Khanna B, Sulzer D, Lindau M (2003) Intracellular patch electrochemistry: regulation of cytosolic catecholamines in chromaffin cells. J Neurosci 23:5835-5845.

Munujos P, Coll-Cantí J, González-Sastre F, Gella FJ (1993) Assay of succinate dehydrogenase activity by a colorimetric-continuous method using iodonitrotetrazolium chloride as electron acceptor. Anal Biochem 212:506-509.

Natori S, Huttner WB (1996) Chromogranin B (secretogranin I) promotes sorting to the regulated secretory pathway of processing intermediates derived from a peptide hormone precursor. Proc Natl Acad Sci U S A 93:4431-4436.

Pascual A, Romero-Ruiz A, Lopez-Barneo J (2009) Differential proteomic analysis of adrenal gland during postnatal development. Proteomics 9:2946-2954.

Sambrook J, Fritsch E, Maniatis T (1989) Molecular cloning. A laboratory manual. Cold Spring Harbor, NY: Cold Spring Harbor Laboratory.

Segura F, Brioso MA, Gómez JF, Machado JD, Borges R (2000) Automatic analysis for amperometrical recordings of exocytosis. J Neurosci Methods 103:151-156.

Smith AD, Winkler H (1967) A simple method for the isolation of adrenal chromaffin granules on a large scale. Biochem J 103:480-482.

Sørensen JB, Nagy G, Varoqueaux F, Nehring RB, Brose N, Wilson MC, Neher E (2003) Differential control of the releasable vesicle pools by SNAP-25 splice variants and SNAP-23. Cell 114:75-86.

Strub JM, Garcia-Sablone P, Lonning K, Taupenot L, Hubert P, Van Dorsselaer A, Aunis D, Metz-Boutigue MH (1995) Processing of chromogranin $B$ in bovine adrenal medulla. Identification of secretolytin, the endogenous C-terminal fragment of residues 614-626 with antibacterial activity. Eur J Biochem 229:356-368.
Taupenot L, Harper KL, O'Connor DT (2003) The chromograninsecretogranin family. N Engl J Med 348:1134-1149.

Videen JS, Mezger MS, Chang YM, O'Connor DT (1992) Calcium and catecholamine interactions with adrenal chromogranins. Comparison of driving forces in binding and aggregation. J Biol Chem 267:3066-3073.

Wegrzyn J, Lee J, Neveu JM, Lane WS, Hook V (2007) Proteomics of neuroendocrine secretory vesicles reveal distinct functional systems for biosynthesis and exocytosis of peptide hormones and neurotransmitters. J Proteome Res 6:1652-1665.

Westermann R, Stögbauer F, Unsicker K, Lietzke R (1988) Calciumdependence of chromogranin A-catecholamine interaction. FEBS Lett 239:203-206.

Winkler H, Fischer-Colbrie R (1992) The chromogranins A and B: the first 25 years and future perspectives. Neuroscience 49:497-528.

Winkler H, Laslop A, Leitner B, Weiss C (1998) The secretory cocktail of adrenergic large dense-core vesicles: the functional role of the chromogranins. Adv Pharmacol 42:257-259.

Yoo SH, Jeon CJ (2000) Inositol 1,4,5-trisphosphate receptor/Ca2+ channel modulatory role of chromogranin $\mathrm{A}$, a Ca2 + storage protein of secretory granules. J Biol Chem 275:15067-15073.

Yoo SH, Lewis MS (1996) Effects of $\mathrm{pH}$ and Ca2+ on heterodimer and heterotetramer formation by chromogranin A and chromogranin B. J Biol Chem 271:17041-17046.

Zhang K, Rao F, Rana BK, Gayen JR, Calegari F, King A, Rosa P, Huttner WB, Stridsberg M, Mahata M, Vaingankar S, Mahboubi V, Salem RM, Rodriguez-Flores JL, Fung MM, Smith DW, Schork NJ, Ziegler MG, Taupenot L, Mahata SK, et al. (2009) Autonomic function in hypertension: role of genetic variations at the catecholamine storage vesicle protein chromogranin B. Circ Cardiovasc Genet 2:46-56. 